\title{
RADICAL AND INCREMENTAL INNOVATIONS AND INNOVATIVE ENTERPRISES IN BULGARIA
}

\author{
Radka P. Ivanova \\ Assoc. Prof. Dr., University of Economics Varna, Bulgaria, r.ivanova@ue-varna.bg
}

\begin{abstract}
Innovation is the result of people's intellectual activity, for which there are no boundaries. This supports the innovation process and is a source of ideas for continuous renewal, the way to overcome market failures, and support the development of organizations. The experience gained allows organizations to make incremental changes faster over time, providing them with competitive advantages. In this regard, the purpose of this material is to examine the characteristics of radical and incremental innovation and to analyze innovative enterprises in Bulgaria.
\end{abstract}

Keywords: Innovation, Radical Innovation, Incremental Innovation, Innovative Enterprises, Bulgaria

\section{INTRODUCTION}

Innovation is important for the development of humanity as a whole. This is further exacerbated in the face of the crisis that the world has been in since the beginning of 2020. Innovation activity is characterized by a high degree of complexity, encompassing the creation, use, and dissemination of innovations to increase the competitiveness of organizations, strengthen their market positions, add new advantages, and expand interests and opportunities. Innovation has a different manifestation, with the result that many classifications are explaining their different aspects and dimensions. At its core undoubtedly lie new discoveries in the field of science and technology, and therefore innovation has the character of progressive, qualitative new changes that manifest themselves in systems and cause change.

\section{RADICAL AND INCREMENTAL INNOVATION - THEORETICAL FOUNDATIONS}

Several innovation studies are looking at their different aspects and characteristics. What we have in common between them all can be highlighted by the emphasis on something new that is created, implemented, used. There is a wide variety of classifications based on different signs in the specialized literature, but it is noticeable that almost all studies talk about two main types of innovation: radical and incremental in terms of the degree of novelty and lag between innovation and practical application (C. Malachias et al. 2013, J. Hervas-Oliver et al. 2019, M. Guisado-Gonzlalez et al. 2015, P. Ritala, P. Hurmelinna-Laukkanen 2013, R. Palmer and R. Brookes. 2002, et all). At the same time, some researchers add to them a third variety called pseudo-innovations (A. Trifilova 2003, p. 29; I. Bichurova 2019, p. 233; Iv. Georgiev, and Ts. Tsvetkov, 1997, p. 40; Kokurin, D. et al., 2011, p. 29, et al.).

V. Dutov (2017) sees radical and incremental innovation as the two opposite ends of a whole, showing the level of knowledge that makes up innovation. In general, we can point out that radical innovation, often referred to as basic, is associated with making fundamental changes in products, services, processes, technologies, methods, etc., i.e. developing new ones. Depending on the period between its creation and their large-scale application, they are subdivided into major innovations of the greatest, medium, and low importance. In turn, incremental innovation implies the modification and improvement of already known and applied technologies, processes, methods, products. The associated costs are also considered to be significantly lower in the capacity of the majority of organizations. This group of innovations in practice lead to the creation of new industrial subsectors, new product assortments, and process modifications, as well as 
rather minor changes. This shows that incremental innovations also vary depending on their degree of innovation, as a result of which there are different ways of developing them (M. Obal, R. KannanNarasimhan, G. Ko, 2016). The radical innovations are revolutionary in nature, leading to serious transformations of the already established order in the daily lives of people and organizations. They require a larger and more diverse information base, effective communications, and relationships with external actors so that they can correctly diagnose potential opportunities and apply non-standard thinking. For their part, incremental innovation focuses on prevailing organizational capabilities, implies the availability of organization-specific information to identify ways of innovation leading to an improvement in the ability to adapt to market changes and at the same time allow for cost reductions.

In regards to the pseudo-innovations mentioned above, it should be clarified that, as their name suggests, they are associated with minor changes which do not lead to increased efficiency from their use; they improve the operation of only part of the system, but reduce the efficiency of the whole system; benefits can only be sought in the short term, whereas in the long term losses or disruptions in the organization occur.

Depending on what type of innovation an organization is carrying out in terms of these varieties, its place in terms of scientific and technical development can be determined. In this regard, we should point out that for Bulgarian organizations this place is mainly related to improved innovation (R. Ivanova, 2018, c. 23).

The practical analysis shows that incremental innovation creates prerequisites for progressive and complex efficiency gains, with lower costs, increased productivity, and the innovation process taking a shorter time to implement it (A. Sorokač, B. Mišota, E. Hyránek, 2016). Each such innovation contributes to achieving functional improvements. It is also considered that incremental innovation improves the capabilities of the persons and organizations implementing them (J. Holck, V. Mahnke, R. Zicari, 2008). The changes to which these innovations lead are highly based on existing knowledge, products, services, technologies, methods, etc., and lead to the improvement of their characteristics. On the other hand, incremental innovation can also be seen as a means of the better disseminating basic innovation in their modified form.

It is an indisputable fact that innovation underpins the competitiveness of each entity. Those with experience gained and a continuous pursuit of improvement have their commitment to innovation processes and can achieve better returns from incremental innovation. This, of course, is also directly dependent on the size of their customer base. On the other hand, in incremental innovation, the quality of the relationships between the members of the teams engaged with them is important for their success. Real-time exchange of ideas and decision-making implies building trust and respect for professional ethics. Relationships within teams have the role of an engine that speeds up the start of the activity and allows for greater integration between tasks, the intervals between their implementation, and something very important - faster and more correctly identifying the problems that the organization has to deal with. These innovations have a lower degree of uncertainty than radical innovation.

The comparison between the two types of innovation also shows that there are differences in terms of organization of work, namely - radical innovation requires a strong leader of the innovation team to provoke others, guide and strictly manage their activities for the organization to become a pioneer among others, while incremental innovation is more important to democratically control the people in the team and achieve moderate sustainability of innovation. As a result, radical innovation allows for the creation of a cardinal novelty, with no analog at the relevant time, providing a long-term competitive advantage and a significant change in market positions, while incremental innovation can only provide short-term advantages with a less significant change in market positions. In radical innovation, the drafting of the project budget and the setting of its duration are characterized by a high degree of complexity, as well as a high risk of failure, as opposed to incremental innovation.

\section{INNOVATION AND INNOVATIVE ENTERPRISES IN BULGARIA}

Bulgaria continues to be in the group of timid (modest) innovators, according to European Innovation Scoreboard 2020. The reason for this can be sought in the limited financial capabilities of the Bulgarian organizations and the lower interest in innovation activity due to the high degree of risk with which it is accompanied, as well as in the unfolding pandemic worldwide. The innovation activity focuses on improvements and modifications, implementation of good practices, which is why innovation in Bulgaria should be assigned to the group of incremental ones. There is still no talk of radical innovation in our country, given the nature of the innovations that have taken place.

The analysis of the data for the period 2014-2018 shows an increase in innovation activity from $26.1 \%$ to $30.1 \%$ in 2018 compared to the 2014 total for the country. The largest share among innovative enterprises in Bulgaria is those of the group of large enterprises, i.e. with a staff of over 250 people (Figure 1). 


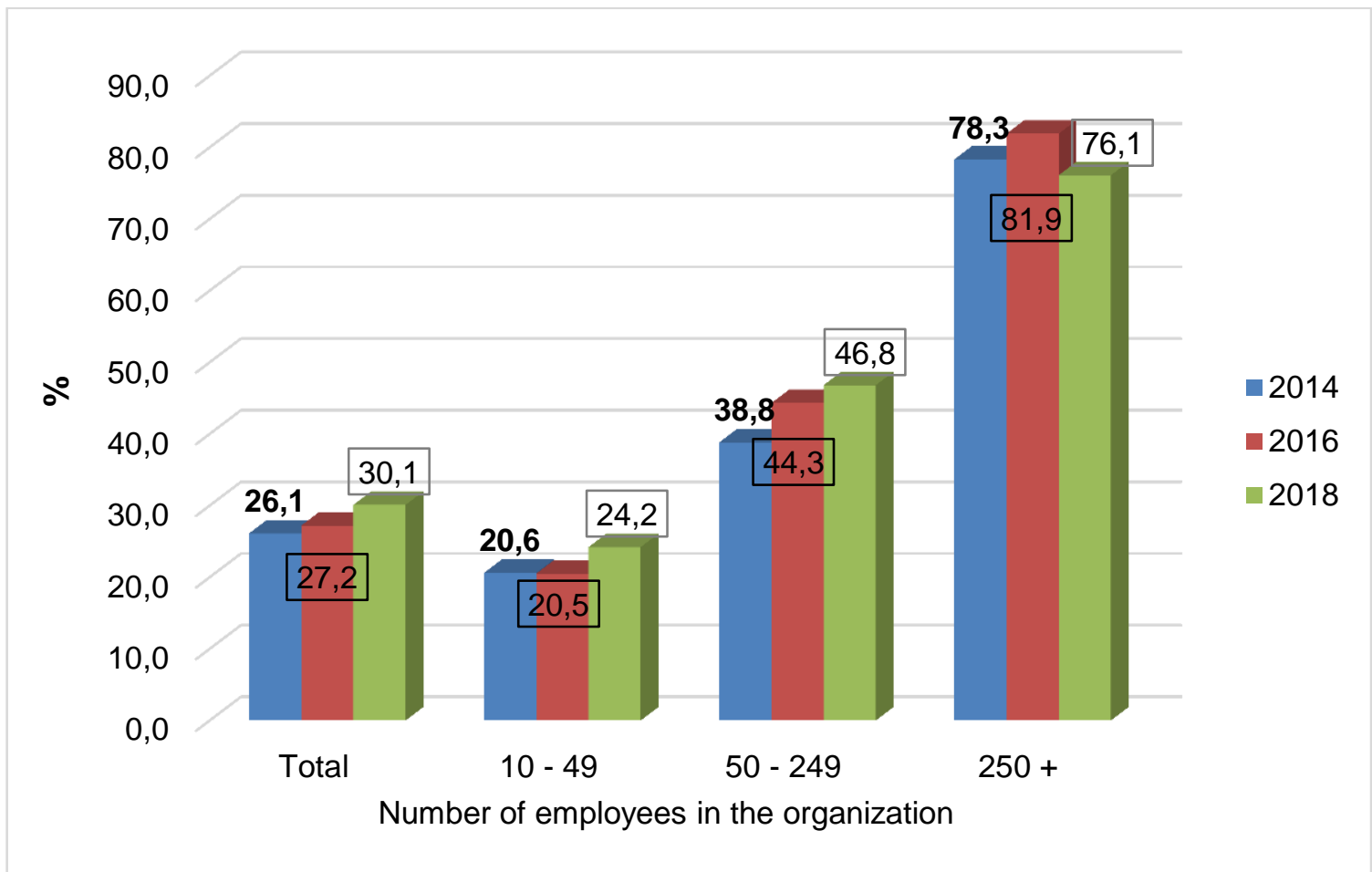

Figure 1. Share of innovatively active enterprises by the total number of enterprises in Bulgaria according to the number of employees employed by them (2014-2018) ${ }^{1}$

An increase in innovative enterprises in Bulgaria has been observed both in the field of industry and services, albeit at different rates (Figure 2). In the field of services, it is lower, but a favorable trend must still be taken into account.

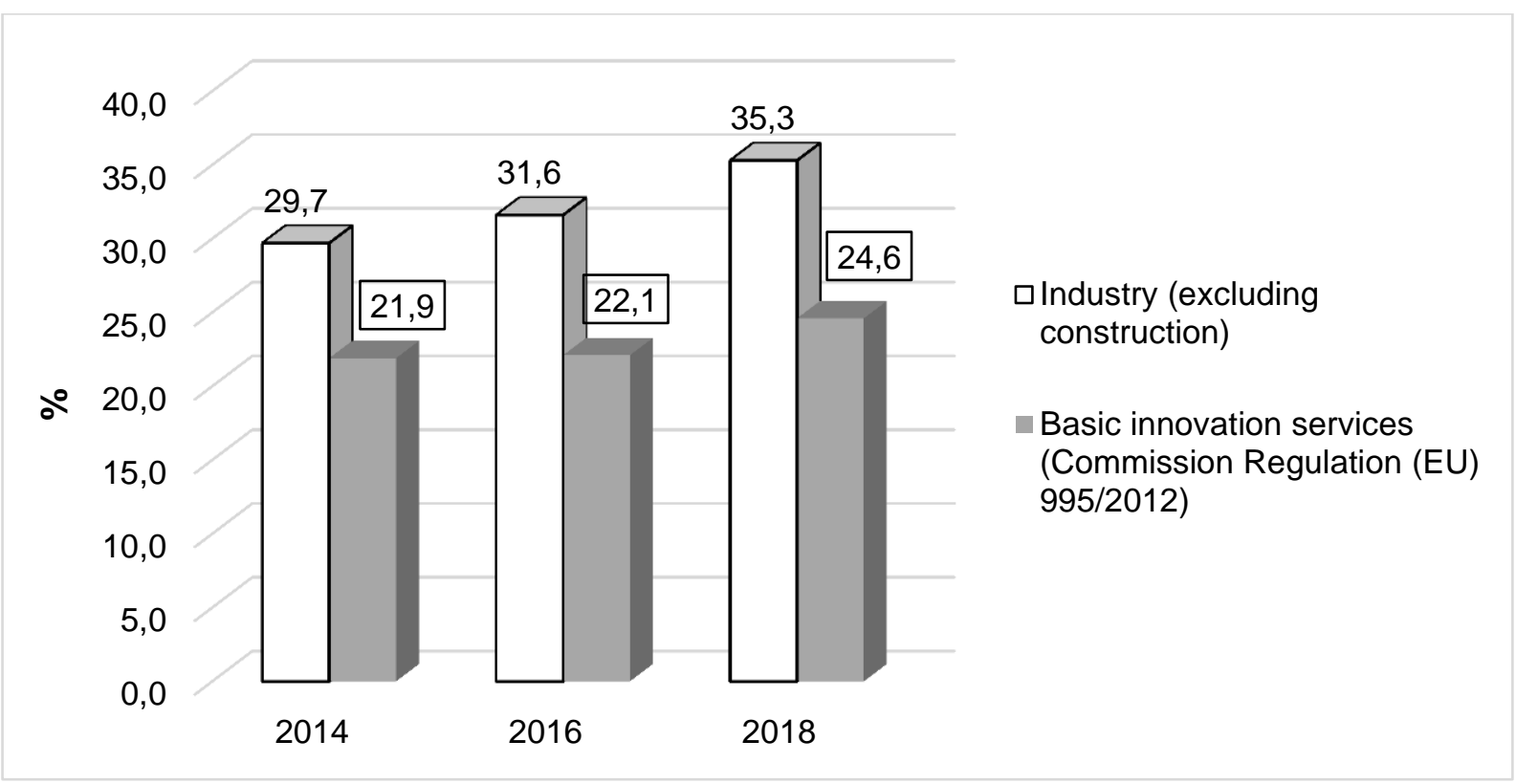

Figure 2. Dynamics of the share of innovatively active enterprises by sector of the total number of enterprises in Bulgaria (2014-2018) ${ }^{2}$

The observed trend is positive, but we should nevertheless point out that it is still insufficient and therefore ways of reinforcing it need to be found. The research and development activities carried out in Bulgaria have

1 The figure was developed according to data from the National Statistical Institute in Bulgaria (NSI).
2 The figure was developed according to data from the National Statistical Institute in Bulgaria (NSI). 
a limited perimeter, which is why the innovations are from the group of new or improved products, new to the market or new to the enterprise. Nevertheless, the accumulated experience in innovation by organizations can also be seen as a prerequisite for seeking new, bolder ideas that will lay the groundwork for developing radical innovation in a subsequent period.

\section{ACKNOWLEDGEMENT}

Each innovation is characterized by scientific and technical novelty, industrial feasibility, economic and commercial efficiency. Carrying out innovation, especially in the face of a crisis, is a complex and difficult process, but it is also a way for organizations to continue to exist, develop, maintain competitive positions and even increase them. For economies that are characterized by more limited opportunities, such as Bulgaria, incremental innovation is more feasible. The observed trend of an increasing share of innovatively active enterprises in the country, albeit with a low growth rate, is favorable. It is, therefore, necessary to make efforts to increase it. In this regard, all stakeholders - institutions, organizations, law enforcement bodies, society as a whole must join forces to stimulate innovation, give a greater impetus to innovation activity, allowing Bulgaria to exit the group of modest innovators, including creating prerequisites for the implementation of radical innovations.

\section{REFERENCE LIST}

Bichurova, I. (2019). Classification of innovations. // KNOWLEDGE - International Journal Vol.30.1 March, 2019, pp. 231-236

Dutov, V. (2017). Drivers and Barriers for implementation radical and incremental innovation in subsea complex in Russia. Dissertation. Nord University.

European Innovation Scoreboard 2020, https://interactivetool.eu/EIS/index.html

Georgiev, Iv., Ts. Tsvetkov. (1997). Management of company innovations and investments. Sofia: Univ. ed. "Economy"

Guisado-Gonz!alez, M., M. Vila-Alonso, M. Guisado-Tato. (2015). Radical innovation, incremental innovation and training: Analysis of complementarity. // Technology in Society. 44 (2016), pp. 48-54.

Hervas-Oliver, J., F. Sempere-Ripoll, S. Estelles-Miguel, R. Rojas-Alvarado (2019) Radical vs incremental innovation in Marshallian Industrial Districts in the Valencian Region: what prevails? // European Planning Studies. DOI:10.1080/09654313.2019.1638887.

Holck, J., V. Mahnke, R. Zicari. (2008). Winning through incremental innovation: The case of MySQL AB. // https://citeseerx.ist.psu.edu/viewdoc/download?doi=10.1.1.579.1084\&rep=rep1\&type=pdf [Accessed 05/07/2021].

https://www.nsi.bg/

Ivanova, R. (2018). Innovation Management. Varna: IK "Gea-Print"

Kokurin, D. et al. (2011). Innovative Economy (management and marketing aspects). Moscow: Economics

Malachias, C., L. Carlos Di Serio, A. Vianna, L. Castro de Carvalho, M. Augusto de Vasconcellos. (2013). Is incremental innovation enough to a company survive in the fast change market such as the technological market? // https://www.researchgate.net/publication/267268483 [Accessed 30/06/2021]

Obal, M. and Kannan-Narasimhan, R. and Ko, G. (2016) Whom Should We Talk to? Investigating the Varying Roles of Internal and External Relationship Quality on Radical and Incremental Innovation Performance. // Journal of Product Innovation Management, 33. pp. 136-147. ISSN 0737-6782.

Palmer, R., R. Brookes. (2002). Incremental innovation: A case study analysis. Journal of Database Marketing Vol. 10, 1, pp. 71-83 Henry Stewart Publications.

Ritala, P., P. Hurmelinna-Laukkanen. (2013). Incremental and Radical Innovation in Coopetition - The Role of Absorptive Capacity and Appropriability. // J PROD INNOV MANAG 2013. 30(1). pp. 154-169.

Sorokač, A., B. Mišota, E. Hyránek (2016). Incremental innovation, performance and financing as key elements in logistic control of construction company. // Innovation Management, Entrepreneurship and 
Proceedings of ADVED 2021- 7th International Conference on Advances in Education

18-19 October, 2021

Corporate Sustainability (IMECS 2016). pp. 689-700.

Trifilova, A. (2003). Management of innovative development of the enterprise. Moscow: "Finance and Statistics" 